\title{
The Research of Sedimentary Micro-facies in PuTaoHua Reservoir of GuLongNan Area
}

\author{
XinYao Ju" a ${ }^{*}$, Lulu Tu² \\ ${ }^{1}$ College of earth science,Northeast Petroleum university,Daqing,Heilongjiang, 163318,China \\ ${ }^{2}$ College of earth science,Northeast Petroleum university,Daqing,Heilongjiang, 163318,China \\ a549818243@qq.com
}

Keywords: GuLongNan area; Sequence stratigraphy; Sedimentary micro-facies; Log phase mode

\begin{abstract}
The research of sedimentary microfacies of PuTaoHua oil layer in GuLongNan region is based on high resolution stratigraphy and sedimentary facies research,On the theoretical guidance of logging geology, sedimentology,establish GuLongNan area high resolution sequence stratigraphy framework, thus to study sedimentary microfacies with core observation described as auxiliary and make full use of drilling core,logging data.This study has established the GuLongNan area PuTaoHua oil layer of high resolution sequence stratigraphy framework,core observation,,single well facies of reservoir,combined with cutting section facies research to have a study with the objective layer of sedimentary microfacies in the studied area plane combination and distribution.
\end{abstract}

\section{Introduction}

GuLongNan region is located in Zhaoyuan,Daqing,Heilongjiang province.East of Xinzhao depression oilfield,Southwest is bounded in Nenjiang and Xinzhan oilfield,Puxi oilfield in the north.Structure located from central depression area Qijia in northern Songliao basin to southern Gulong depression.At the top of the PuTaoHua reservoir developing 7 Level 3 tectonic units of Xinzhao,Xinzhan,the north of Ao is nose structure,GuLong syncline,Maoxing,Yingtai slope.Overall performance of the structure of the "three noses two depressions with a slope" pattern.

\section{The establishing of high resolution sequence stratigraphy framework}

The basic theory of high resolution sequence stratigraphy. High resolution sequence stratigraphy proposed by professor Cross in Colorado college of mining. In the mid 1990s, introducing the theory of domestic by hong-wen deng and quickly obtained the development and innovation. The theory by combining core, outcrop, well, the earthquake, the drilling of one dimensional information into a 3D strata relations, building area, oil field so that the cause of the reservoir level reservoir stratigraphic framework, the opposite - storage - cover distribution to evaluate and predict a new theory.

Partition and the identification marks of sequence interface. Combined with well logging and core, lithologic facies marks, detailed study we determine the level 4 and 5 sequence boundary, this study divided the minimum sequence unit for six levels of sequence, consists of short-term base level cycle, which is equivalent to small layers in sandstone group.

Cet 4 sequence interface identification and division 
Y1SB4 interface on my log in depth on dual laterolog to slow down the steep asymmetric at the bottom of the "V" glyph mudstone low-value, acoustic curve and natural gamma curve on "W" type low to high values of inflection point. Divided into the bottom of the dark grey mudstone on lithology, the prograde and retrogradation conversion surface.

Fifth and sixth sequence interface identification and classification

According to the needs of oilfield development, we to six P I oil group sequence (i.e., small layers) segmentation, make the consensus 9 six levels of sequence interface, respectively corresponding to PI8 PI1 top from bottom to top. Of PuTaoHua oil layer of internal PI8, PI5, PI2, PI1 top six levels of sequence interface, respectively, with five sequence interface Y1SB1, Y1SB2, Y1SB3, Y1SB4 overlap. As a result, the objective interval P I groups can be further subdivided into eight six levels of sequence, bottom-up P I $8 \sim$ P I 1 respectively.

High resolution sequence stratigraphic isochronous contrast. In this study, to get rid of the conventional small layers according to the single sand body flow unit division owe reasonable practice, according to the cycle of contrast, sequence segmentation, the principle of cascade control division of reservoir group, sandstone, small, until the single sand layer, or layer 4 sequences corresponding to the reservoir group (composed) medium-term cycle sequence corresponds to sandstone, five groups (made up of short cycle), six levels of sequence corresponds to small layers (made up of super short term cycle).

Placanticline region bottom-up development of lower cretaceous DengLouKu group and QuanTou group,QingShanKou formation, YaoJia, NenJiang group, upper cretaceous square table set, MingShui group, the top formation, TaiKang group and quaternary. The YaoJia is a objective interval.

Northern section in the study area well Da428- well Da414- well Da146 - well Mao231 - well Gu692, Well Gu Shen 1, according to the work area the east sag tectonic belt in PuTaoHua oil layer formation hypoplasia, basic formation development in western China is full, the top-down development P I up, P I middle ,P I down on sandstone under the group, East formation is missing.

Base level cycle of sedimentary evolution and formation. Under P I down sandstone formation sedimentary period, shallow water, northwest to accept deposits in the study area, and the eastern parts of no deposit or under denudation, to P I middle sandstone formation sedimentary period, the sedimentary range expansion, sent copies to P I down sandstone formation sedimentary period, as the further expand water, sediment and further to the west bank back deposit, sand body gradually thinning, formed the PuTaoHua oil layer on the unconformity on the surface of the intermittent type deposit.

PuTaoHua formation in general and thinner gradually from northwest to southeast in the study area, thickness change is bigger. Through stratigraphic classification and correlation, reveals the PuTaoHua reservoir formation evolution regularity in the study area, for further developing GuLongNan region overall research of sedimentary facies and reservoir quality skeletal sand body reveals laid a solid foundation.

\section{The sedimentary microfacies of reservoir}

Coring Wells in the studied area are the basis of core observation, combining previous research results and related data, by the high resolution sequence stratigraphy, sedimentary petrology and petroleum geology theory as the instruction, classic sign of sedimentary facies in the studied area, single well sedimentary facies and source system has carried on the thorough analysis and discussion, 
in the end of the study area sedimentary system has formed a relatively comprehensive understanding. In PuTaoHua oil layer sedimentary period, to shore and shallow lake sedimentary environment in the study area, the main sedimentary delta front sand body.

Provenance analysis. Analysis GuLongNan areas in PuTaoHua reservoir sand than the equivalent figure features can be seen, sandstone percentage showed high northwest, north, south east direction gradually reduce, thus can generally reflect the provenance of PuTaoHua oil layer is located in the north and west in the study area

The establishment of the sedimentary microfacies types and logging facies model. Sedimentary microfacies types:

The genetic types of reservoir sand body in the study area is more, according to the different sedimentary microfacies, specific include: delta front part are mainly underwater distributary channel, mouth bar sandbody, frontal sheet sand body and underwater crevasse splay sand body; Shore shallow lake beach, a few parts of the dam.

Microfacies type analysis and the establishment of the logging facies model:

Comprehensive core observation and well logging curve characteristics research, established the GuLongNan area reservoir sedimentary microfacies recognition litho-electric relationship, build the delta front of various kinds of microfacies recognition of log facies pattern (Fig. 1), as the research area of single well sedimentary microfacies identification research and plane and profile sedimentary microfacies research provides the basis.

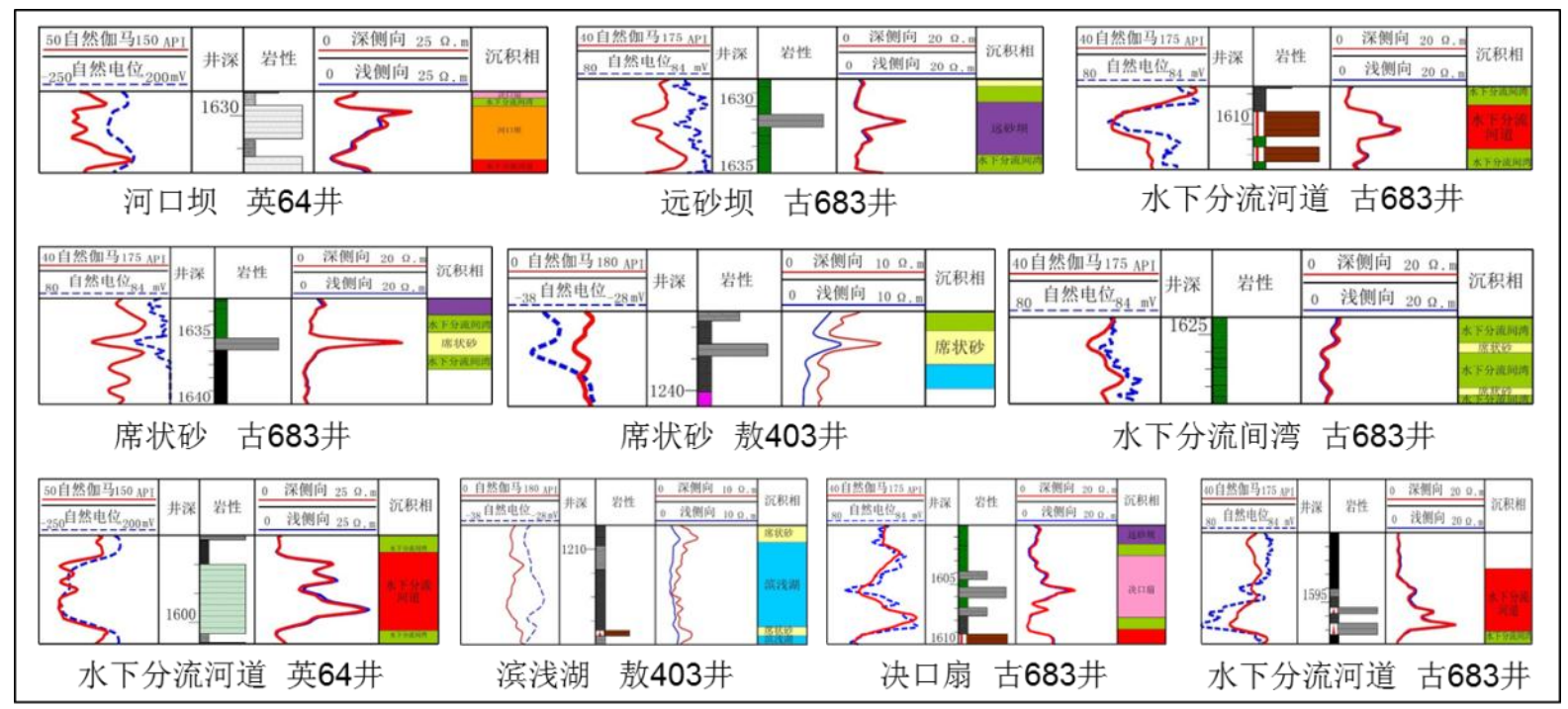

Fig. 1 GuLongNan PuTaoHua reservoir microfacies main logging facies model

Single well sedimentary microfacies research. Ying 64:

This section is the core of the mudstone is both dark mudstone, have black and dark mudstone, shows a relatively deep water, lake delta front deposition.

Ying331:

This section is the core of the mudstone is both more dark mudstone, have black and dark mudstone, shows that the 64 relatively deep water, lake delta front deposition.

The research of section sedimentary microfacies. This study were done between facies types are mainly underwater distributary channel, distributary bay and sand sheet. The north and west from the profile of the contrast between the because close to the source, channel is more, the scale is larger, the farther south sand sheet increased, less river; From the vertical, in the upper sand body thicker, 
narrow channel width, profile on performance for lenticular, overall performance characteristics for balling sand.

The plane distribution of sedimentary microfacies are characteristics. The overall look, from PI8 to small layer PI1 sedimentary period, on the whole, first becomes shallow water depth, and darker trend in the PI3 sedimentary period, shoreline. Area are mainly delta front and littoral and shallow lake facies. Northern provenance growth of underwater distributary channel advantage is better than that of the west provenance growth channel, but river stretch farther, cover extending scope is bigger.

Through the above analysis thinks, PuTaoHua reservoir sedimentary period, favorable sedimentary facies sand body types are mainly underwater distributary channel and sand sheet. Overall performance for water body becomes shallow gradually, and the water back into the product, to deepen, sedimentary sequence of shrinking.

\section{The distribution regularity of sand body}

Through the above research, we may safely draw the distribution of sand body in the study area with the following rules:

Thickness of sand body as a whole is bigger, the thickness can be up to $20 \mathrm{~m}$ wide area; In addition to the southern study area has sand body development.

Uneven distribution of thickness of sand body in the plane of the northwest thick, thin southeast trend.

Comprehensive core observation and the results of the research of sedimentary facies, sand body of the distribution is mainly controlled by source and sedimentary facies.

Pdown and Pup on the thin sand body, small ranges, $\mathrm{P}$ medium sand body thickness, distribution range, this is mainly controlled by the vertical evolution law.

\section{Conclusion:}

Guided by the high resolution sequence stratigraphy, on the whole system layer, is divided into eight small layers. Has been clear about the content source direction, main material source as the northern provenance. The overall performance in the study area for water body becomes shallow gradually, the water back into the product, to deepen, sedimentary sequence of shrinking. The main sand body in the study area is an underwater distributary channel, mouth bar and sand sheet. Uneven distribution of thickness of sand body in the plane of the northwest thick, thin southeast trend. Sand body of the distribution is mainly controlled by source and sedimentary facies . Pdown and Pup on the thin sand body, small ranges, $\mathrm{P}$ medium sand body thickness, distribution range, this is mainly controlled by the vertical evolution law.

\section{References}

[1]Liuzongbao,Mashizhong,Sunyu,etc. Sanzhao sag of PuTaoHua oil layer of high resolution sequence stratigraphic classification and the study of sedimentary characteristics[J]. Journal of sedimentary,2008,26(3):399-406.

[2]CartwrightJ,Huuse M.3D seismic technology:the geological'Hubble'[J].Basin Research,2005,17:1-20. 
[3]Vail P R,Audemard F,Bowman S A,etc.The stratigraphic signatures of tectonics,eustasy and sedimentology-an overview[J].In:Einsele G,RickenW,Seilacher A,eds.Cycles and Events in StratigraPhy[M].Springer-Verlag,1991:617-659.

[4]Dickinson W R.Plate tectonics and sedimentation[A].In:Dickinson W R,ed,Tectonics and sedimentation[M],SEPM Special Publications,1974,22:1-27.

[5]Dickinson W R.Plate tectonics and sandstone compositions [J].AAPG Bulletin,1979,63(12):2164-2182.

[6]Crook D A W.Lithogenesis and geotectonics:the significance of compositional variations in flysch arnites[A].In:Dott $\mathrm{R}$ H,ed,modern and ancient geosynclinals sedimentation[M],SEMP Special Publication:1974,19:304-310.

[7]Leggett J D,Zuffa G G X.Marine clastic sedimentary;concepts and case studies.1991,Graham-Trotman.

[8]Pickering $\mathrm{K} \quad \mathrm{T}$,et al.Deep marine environments,clastic sedimentary and tectonic, 1989.Unwin-Hyman.

[9]T.A.Cross,M.R.Maker,et al.Applications of High-resolution Sequence Stratigraphy to Reservoir Analysis[J].In:proceedings of the 7th Exploration and Production Research Conference.1993,P5.11-13.

[10]Andrew D.Miall,Charlene E.Miall.Sequence stratigraphy as a scientific enterprise:the evolution and persistence of cenficting paradigms[J].Earth-Science Reviews,2001,54:21-48. 